\title{
Implementation of Team Teaching in Selected Tertiary Institutions in Nigeria
}

\author{
Osuala, Rita Chigozie (PhD)
}

Psychology Department (Measurement \& Evaluation), Alvan Ikoku University of Education, Owerri, Nigeria

Osualarita@yahoo.com

\section{Onwuagboke, Bede Blaise Chukwunyere}

Department of Curriculum and Instruction, Alvan Ikoku University of Education Owerri, Nigeria bbconwu@gmail.com

\section{Chukwudebelu, Chinwe Bridget}

Department of Educational Foundations/Administration, Alvan Ikoku University of Education, Owerri, Nigeria chiokifarms@gmail.com

\author{
Doi:10.5901/jesr.2015.v5n3p221
}

\begin{abstract}
The study was a descriptive survey that sought to evaluate the implementation of team teaching in federal tertiary institutions in a state in Nigeria. A sample of 1,110 lecturers was selected from the population using stratified random sampling technique. Four research questions guided the study. A set of researchers designed questionnaire in form of 4-point Likert scale, was used for data collection. The validity as well as the reliability was ensured by using experts in Curriculum and Instruction from a university and trial testing. The data obtained yielded a reliability index of 0.85 using Cronbach Alpha statistics. The research questions were answered employing descriptive and inferential statistics. The findings revealed that lecturers in federal tertiary institutions practice team teaching in their lecture delivery to a low level; on the other hand, they implement team-teaching principles in evaluation of students' performance. Several reasons were found to be responsible for low implementation of team teaching in instructional delivery with no significant difference in mean implementation among lecturers according to gender. It was recommended, among others, that some lecturers, especially the junior ones, should remove complex among them and build up the psyche that they are equal to the task even in the midst of others.
\end{abstract}

Keywords: Team teaching; Implementation; Tertiary Institutions, Nigeria.

\section{Introduction}

Tertiary education plays a key role in the economic and social development of any nation. Oyedele (2009) citing World Bank (2002) noted that in today's life-long learning framework, tertiary education provides not only high level skilled manpower necessary for every market but also the training essential for teachers, doctors, nurses, civil servants, engineers, scientists and other personnel. It is these trained individuals that help to develop every sector of the economy and make important decisions which affect the entire society. For tertiary education in Nigeria to play the above role, especially in this $21^{\text {st }}$ century, attention must be paid to the effective implementation of tertiary education programmes and policies. Obviously, the outcome of any educational programme is usually a reflection of what goes on in the classroom in form of teaching and learning. For a learner to grasp any segment of knowledge, effective instructional techniques are very vital. One of these effective techniques is team teaching.

Contextually, team teaching has been described by different scholars. It has been defined as working together of two or more teachers in order to guide an individual learner or a group of learners toward a set of aims or objectives, (Japanese Ministry of Education, Science, Sports and Culture, 1994). It is an approach which involves true team work between two or more qualified instructors who together make presentations to an audience. Team teaching involves a group of teachers working together, planning, conducting and evaluating the learning activities for the same group of students. Scholars have noted that there are many categories of team-teaching, going from teachers dividing up lecture blocks between or among them (the serial approach) to teachers continually planning, presenting, and evaluating lectures together (the collaborative approach) (Carpenter et al. 2007). 
In team teaching, problems are defined clearly; there is time for brainstorming alternatives for actions. In practice, team-teaching has many different formats but in general it's a means of organizing staff into groups to enhance teaching and learning. Teams generally comprise staff members who may represent different areas of subject expertise but who share the same group of students and a common planning period to prepare for teaching (Centre for the Enhancement of Learning and Teaching1998). Effective team teaching requires a re-orientation on the part of individual staff members and departmental administrations.

The importance of team teaching as a method of instructional delivery in tertiary education has been stressed because of many advantages both on the part of the students and the lecturers. Through team teaching, teachers can develop their approaches to teaching and acquire a greater depth of understanding of the subject matter of the unit or module. Suffice it to say that peer observation has been seen as a means to improve teaching while meeting the wider needs of student diversity and global competition amongst universities, along with the suggestion that such innovations should be formalised by management (Carroll \& O'Loughlin 2013). This is in tandem with the suggestion of Knight, (2013) that flexibility and innovation are required at a global level to address this rapidly changing landscape. Team teaching also provides opportunities for new teachers to obtain greater opportunities of learning to teach (Roth et al., 2004).

On the part of the students, team teaching provides them with a greater sense of identity, belongingness and support. Research has also found that team teaching enhances the achievement of the learners (Jang, 2006). In most cases, students' interest in learning is increased due to the stimulation created by viewing more than one individual teacher at work. Exposure to the views and skills of more than one teacher can help students develop more mature understanding of knowledge which would have been problematic. In some instances, team teaching has been employed in secondary schools in order to tackle specific problems, such as low student motivation and discipline problems (Storey et al. 2001). Carpenter et al.'s (2007) have rightfully argued that the collaboration of multiple teachers build a richer learning environment, due to many perceptions and more efficiently providing for individual learning needs. This can ultimately result to better students' performance in terms of greater independence and assuming responsibility for learning. Though team teaching creates room for collaboration among team mates, however, not all team teaching methods offer same opportunities to nurture collaboration and enhance teachers' professional development (Jang, 2006).

Despite these numerous merits outlined, team teaching can be a source of frustration if its goals are not realistic, meetings are not productive and decision-making is not well handled by team leaders. Implementing a team teaching approach requires administrative encouragement, acceptance of an initial experimental quality and willingness to take risks. Team teaching implementation boarders on management issues such as who will lead the team, who will be in the team, what will be expected and in what time frame, how will meetings be conducted, how will teaching activities and events be actually planned and so on. Teams need to have a sense of direction. When teams are formed from teachers who have no previous team experience, it seems to take about three years for them to develop team teaching process to an effective and efficient level (Quin \& Kanter, 1984). However these pitfalls can be avoided if adequate staff development support is available. The relative complexity demands which team teaching places on teachers are recognized both by the individual themselves and their departmental leader. Team teaching needs enough time to develop into various stages of development (Centre for the Enhancement of Learning and Teaching1998). According to Nunan (1992) the hope of collaborative teaching achieving success depends on three conditions: if teachers possess or are supported to develop appropriate skills; there is time for the implementation of team teaching; and the existence of appropriate administrative or management support. It is when these three conditions are present in any learning environment that we look forward to a successful team teaching implementation.

Although the staff mentoring system is not new in higher education, as it has been used as an instrument of general professional development for new lecturers (Angelique, Kyle \& Taylor 2002). In Nigeria however it has been adopted as one of the measures to improve quality standard of tertiary education. Team teaching was introduced as an innovative and effective teaching technique with the main objectives of:

- Providing a supportive environment that overcomes the isolation of working in self-contained or departmentalized class-rooms. Exposing lecturers to the subject expertise of colleagues, to open critique, to different styles of planning and organisation, as well as methods of class presentation, teachers can develop their methods to teaching and reach a deeper understanding of the subject matter of the unit or module.

- Ensuring better student performance in terms of greater independence and assuming responsibility for learning. This can be achieved by exposing them to views and skills of more than one lecturer making room for the development of a more mature understanding of knowledge often being problematic rather than right or wrong. 
- Supporting the professional and interpersonal dynamics of departments resulting in closer integration of faculty (Centre for the Enhancement of Learning and Teaching, 1998).

These objectives can only be achieved if lecturers should implement team, teaching to its fullest in their lecture delivery as well as evaluation of students' performance which includes continuous assessment (CA), exam marking and reporting.

However, the extent to which tertiary education in Nigeria have been able to achieve these lofty goals of team teaching has remained uninvestigated. The extent to which the objectives of a particular educational programme are achieved depends very much upon effective evaluation. It is the evaluation of performance that provides opportunity for discovering the strengths and weaknesses of a programme in terms of pre-stated objectives (Edem, 2003). For team teaching to make positive contributions to the quality of learning and staff development there has to be an effective evaluative procedure to measure its effectiveness and workability in institutions of higher learning. Evaluation is simply making value judgment about an objective. It is the systematic collection and analysis of data to know the extent learning objectives have been or are being achieved in order to make value judgment (Osuala 2012). In other words, evaluation offers a way of determining whether an initiative has been worthwhile in terms of delivering what was intended.

In a $21^{\text {st }}$ century classroom which is innovation driven, collaboration has been recognized as essential for both the teacher and the learner. Team teaching is recognized as an innovative and effective teaching technique. Most tertiary institutions in Nigeria have adopted and insisted that lecturers teach in teams as an instructional strategy to mentor younger colleagues, ensure effective instructional delivery, collaboration and minimize corrupt practices. The manner in which this is implemented has been of concern to institutions management. One then wonders if the objectives of team teaching are being realized and if not, what could be the problem. As laudable as team teaching is to tertiary education, not much has been recorded to emphasize its implementation in the area of evaluation (Oni, 2000). This is because no matter how laudable an educational programme is, if there is no laid down plan to evaluate its implementation; the programme is bound to be fruitless.

Since the introduction of the team teaching principles in these institutions, there seem to be no research efforts directed towards ascertaining how it is implemented in the various institutions across the country. Hence the researchers have undertaken this study to fill the research gap. In the light of the above, this study evaluates the extent to which lecturers in federal tertiary institutions in Imo State Nigeria implement team teaching.

Generally, the study is the evaluation of the implementation of team teaching by lecturers in federal tertiary institutions. Specifically, the study seeks to determine:

(i) The extent of implementation of team teaching principles in instructional delivery in federal tertiary institutions.

(ii) The extent of implementation of team teaching principles in evaluating students' performance (continuous assessment, examination, marking and reporting) in federal tertiary institutions.

(iii) Reasons why some lecturers in federal tertiary institutions avoid team teaching.

(iv) Effects of gender on implementation of team teaching by academic staff in tertiary institutions

Sequel to the objectives stated above as the intent of this study, the following corresponding research questions were asked to direct the study.

(1) To what extent do lecturers in federal tertiary institutions in Imo State implement team teaching in their instructional delivery?

(2) To what degree do lecturers in federal tertiary institutions implement team teaching in evaluation of students' performance (CA, exam, marking and reporting)?

(3) Why do some lecturers avoid team teaching in federal tertiary institutions in Imo State?

(4) Does gender have any effect on the implementation of team teaching by lecturers in tertiary institutions?

\section{Research Methods}

The study employed descriptive survey design. The population of the study comprised all the lecturers in the three known federal tertiary institutions in Imo State namely: Federal University of Technology Owerri (FUTO), Federal Polytechnic Nekede and Alvan Ikoku Federal College of Education Owerri. In the three federal institutions, the lecturers are about 5,551 (five thousand, five hundred and fifty one) for both male and female lecturers (Source: Senior Staff Personnel Office of the three institutions, 2015). From the population, of the lecturers in each institution, 400 lecturers were randomly drawn to make up the sample size of 1200 respondents.

The instrument for data collection was a researchers designed questionnaire tagged "Team Teaching Implementation Questionnaire (TTIQ)". It is made up of two sections; A and B. Section A contains five items on the 
lecturers' demography. Section B contains ten items on each of the research questions on the extent of team teaching implements ton. The questionnaire was a four-point Likert scale which bears the options and weight as Strongly Agreed (SA) - 4, Agreed (A) - 3, Disagreed - 2 and Strongly Disagreed - 1 for positively skewed items, but for negatively skewed items, the reverse was the case. The validity of the instrument was ensured by panel of 3 experts, 2 from the Department of Curriculum Studies and 1 from the Department of Measurement and Evaluation. The comments of the experts led to modifications of the items. The reliability of the instrument was calculated using Cronbach Alpha statistics after trial testing which yielded an index of 0.85 which implied that the instrument has a good internal consistency and therefore reliable.

Out of the 1200 questionnaires distributed, 1110 were returned properly filled out and was used for data analysis. The IBM statistical package for social Sciences (SPSS) version 22 was used to analyze the data. The data collected was presented using frequency tables. Data analysis was done and descriptive and inferential statistics was used to answer the research questions. The benchmark for accepting or rejecting any variable as significant was set at mean 2.5 for research questions 1 to 3 . Therefore, any variable with a mean of 2.5 and above is deemed significant and of high level while anyone with a mean below 2.5 is not significant and therefore of low level. Research question 4 was however answered using independent samples T-test.

\section{Results}

\subsection{Research Question One}

To what extent do lectures in federal tertiary institutions in Imo State deliver their lectures through team teaching? Means and standard deviations were employed to answer the above research question. Data displayed in table 1 revealed that the major principles of team teaching discussed in background of this study are not followed in the implementation of team teaching in the institutions used for the study.

Table 1: Mean responses of lecturers on extent of Implementation of Team teaching in instructional delivery

\begin{tabular}{|c|c|c|}
\hline & Mean & Std. Deviation \\
\hline Lecturers are usually paired for teaching and supervision of courses & 11103.1685 & .90260 \\
\hline Lecturers usually go in group as a team for lectures & 11101.6180 & .79790 \\
\hline Lecturers share topics and time and only go to lectures when it is their time & 11103.1994 & .90663 \\
\hline Lecturers share instructional duties during lectures & 11101.8577 & .95880 \\
\hline Senior team mates are always available during lectures & 11101.8640 & .92284 \\
\hline Senior colleagues adequately mentor junior colleagues in the team & 11101.6432 & .81284 \\
\hline Mean Team Teaching Implementation & 11102.2251 & .50847 \\
\hline
\end{tabular}

The data showed that although lecturers are paired in teams however $(M=3.2, S D=.9026)$ these lecturers hardly go to lectures together $(M=1.6, S D=.80214)$. The common practice is either that the lecturers share the topics and times so as to lecture in turns $(M=3.2, S D=.90801)$ or senior lecturers direct the junior ones to do the teaching without supervision $(M=1.9, S D=.92284)$ and the much needed mentoring $(M=3.2, S D=.87940)$. The implication of the above is that the level of implementation of team teaching in these institutions for instructional delivery is low.

\subsection{Research Question Two}

To what degree do lecturers in federal tertiary institutions in Imo State implement team teaching in evaluation of student's performance (CA, exam, marking and reporting)?

On the issue of the degree of implementation of team teaching principles in the evaluation of instructional outcome, table 2 is used to display the result of the statistical analysis. 
Table 2: Level of implementation of team teaching during course assessment

\begin{tabular}{lr}
\hline \hline & N Mean $\begin{array}{c}\text { Std. } \\
\text { Deviation }\end{array}$ \\
\hline All members in a teaching team are involved in setting of assignment, tests and examination items & 11103.2777 .82732 \\
All members in a teaching team share and mark exam scripts & 11103.1703 .86345 \\
Administration of continuous assessments and examination are done as a team & 11103.2090 .84588 \\
Collation of students' scores is a shared responsibility among team members & 11102.9477 .85303 \\
Team mates usually meet to produce marking guides for marking of assignments, tests and examination scripts 11103.1741 .89987 \\
Team leaders/coordinators vet question items as well as marked scripts by junior colleagues before reporting & 11103.21171 .23492 \\
Mean Team teaching Implementation in Evaluation & 11103.1651 .47909 \\
\hline \hline
\end{tabular}

The findings show that team work is involved in virtually all the evaluation aspects of instruction such giving out assignments, and setting of tests and examination questions (Mean $=3.27, \mathrm{SD}=.83$ ); marking of examination scripts (Mean = 3.17, SD = .86); administration of continuous assessments and examinations (Mean $=3.2, \mathrm{SD}=.85$ ). The grand mean of implementation of the principles of team teaching in students' evaluation is (Mean= $3.17, \mathrm{SD}=.48$ ) indicating high degree of implementation in the institutions. The result goes to show that the objective of team teaching is may reach high level of achievement in the area of evaluating students' performance.

\subsection{Research Question Three.}

Why do some lecturers avoid team teaching in federal tertiary institutions in Imo State?

Data presented in table 3 displays the respondents' views on the reasons why lecturers in the institutions studied would most probably avoid team teaching. They include avoidance of embarrassment from team mates (Mean $=3.3, \mathrm{SD}$ $=.83$ ); Lack of control and adequate sanctions for non-compliance (Mean $=3.1, \mathrm{SD}=.90)$; To have opportunity to engage in corrupt practices (Mean $=3.2, \mathrm{SD}=.84$ ) among others.

Table 3: Mean ratings of reasons why lecturers avoid team teaching

\begin{tabular}{lccc}
\hline \hline & $\mathrm{N}$ & Mean & Std. Deviation \\
\hline Avoidance of embarrassment from team mates during lectures & 1110 & 3.2658 & .82598 \\
Lack of control and adequate sanctions for non-participants & 1110 & 3.1441 & .89530 \\
Lack of collaborative skills & 1110 & 3.0793 & .91723 \\
Lack of adequate knowledge of Innovative teaching techniques & 1110 & 2.7387 & .98328 \\
To have opportunity to engage in corrupt practices & 1110 & 3.2342 & .83601 \\
Obsession with individuality & 1110 & 2.8144 & 1.00664 \\
Lack of self-confidence to lecture in the midst of colleagues & 1110 & 3.0342 & .93750 \\
Lack of rewards for outstanding team performance & 1110 & 2.8495 & 1.01115 \\
\hline \hline
\end{tabular}

\subsection{Research Question Four.}

This research question sought to determine if differences exist in mean implementation of team teaching in the institutions used for the research due to gender. Data displayed in table 4 shows that there is no significant difference between male $($ Mean $=2.6833, \mathrm{SD}=.41349)$ and female $($ Mean $=2.7143, \mathrm{SD}=.40161, \mathrm{t}(1108)=-1.260, \mathrm{p}=.21$ two tailed) in implementation of team teaching.

Table 4: Independent Samples t-test of equality of means on implementation of team teaching

\begin{tabular}{|c|c|c|c|c|c|c|c|c|c|}
\hline & \multicolumn{3}{|c|}{$\begin{array}{l}\text { Levene's Test for } \\
\text { Equality of Variances }\end{array}$} & \multicolumn{4}{|c|}{ t-test for Equality of Means } & & \\
\hline & \multirow[t]{2}{*}{$\mathrm{F}$} & \multirow{2}{*}{ Sig. } & \multirow{2}{*}{$\mathrm{t}$} & \multirow[t]{2}{*}{ df } & \multirow{2}{*}{$\begin{array}{l}\text { Sig. (2- } \\
\text { tailed) }\end{array}$} & \multirow{2}{*}{$\begin{array}{l}\text { Mean } \\
\text { Diff. }\end{array}$} & \multirow{2}{*}{$\begin{array}{l}\text { Std. Error } \\
\text { Diff. }\end{array}$} & \multicolumn{2}{|c|}{$\begin{array}{l}95 \% \text { Confidence } \\
\text { Interval of the Diff. }\end{array}$} \\
\hline & & & & & & & & Lower & Upper \\
\hline Equal variances assumed & .429 & .513 & -1.260 & 1108 & .208 & -.03101 & .02460 & -.07927 & .01726 \\
\hline Equal variances not assumed & & & -1.264 & 1082.986 & .207 & -.03101 & .02454 & -.07915 & .01714 \\
\hline
\end{tabular}

The magnitude in the difference of the means (Mean difference $=-.031,95 \% \mathrm{Cl}:-.07927$ to .01726 ) was rather too small. 


\section{Discussion}

The results of this study have revealed that lecturers in federal tertiary institutions in Imo State are paired/ grouped/teamed in a course but hardly practice team teaching in their instructional delivery. This low level implementation of team teaching at the level of curriculum implementation has obvious implications. This therefore implies that some of the lofty objectives of team teaching are not achieved. Mentoring of junior lecturers which is one of the objectives and benefit of team teaching (Roth et al., 2004) is rarely achieved if lecturers divide topics and take turns in teaching. The collaboration fostered through team work in a teaching environment which enriches teachers knowledge (Jang, 2006) as well as the students' experience leading to better knowledge creation and achievement (Carpenter, et al. 2007) is hardly realised.

Team work found to be implemented by Lecturers in federal tertiary institutions in the area of evaluation of students' performance is a welcome development. The implication is that assessment of students' performance is free from subjectivity and bias thereby creating room for objectivity in assessment.

Findings show some of the reasons why some lectures in federal tertiary institutions avoid team teaching. These reasons are mostly based on complex on lecturers' part. For instance lack of self-confidence to deliver instruction in the presence of colleagues does not arguer well for academics of the $21^{\text {st }}$ century who should lead the way in collaboration for improved learning. It was also revealed that there is no measures put in place to check non-compliance with the implementation on the part of the institutions' administration. This is most probably the most probable reason why some academic staff avoids team teaching. One thing is to make a policy and another to monitor effective implementation, if the management of these institutions creates an effective monitoring and reporting system, the compliance by lecturers will appreciably rise. The implementation of this innovation in the learning space was not affected by lecturers' gender. This is a good sign that team teaching is implemented by both male and female lecturers alike.

\section{Recommendations}

Based on the findings of this study, the researchers recommend that workshops, seminars and conference should be organized by institution authorities, in order to create awareness to lecturers about team teaching as an innovative and effective method of lecture delivery. These fora will acquaint them with the objectives of team teaching and equip them with requisite skills for its' effective implementation in instructional settings.

Some lecturers, especially the junior ones, should remove complex among them and build up the psyche that they are equal to the task even in the midst of others. Team teaching should be effectively monitored by Heads of every department to ensure strict compliance in order that the expectations of implementation achieve its objectives. Senior lecturers paired with the junior ones should see it as an opportunity to mentor them rather than an avenue to intimidate and embarrass them in front of the students while teaching but rather, guide, correct and advice them on their mistakes privately.

\section{References}

Alexander, W. M. (1995). The junior high school: A changing view. Middle School Journal, 26(3): 20-24.

Angelique, H. Kyle, K. \& Taylor, E. (2002). Mentors and muses: new strategies for academic success. Innovative Higher Education, 26(3), 195-625. doi:http://dx.doi.org.dbgw.lis.curtin.edu.au/10.1023/A:1017968906264.

Carroll, C. \& O'Loughlin, D. (2013). Peer observation of teaching: enhancing academic engagement for new participants. Innovations in Education and Teaching International, 50(1), 1-11. doi: http://dx.doi.org/10.1080/14703297.2013.778067.

Carpenter, D. M., Crawford, L. \& Walden. R. (2007). Testing the efficacy of team teaching. Learning Environments Research, 10, 53-65.

Centre for the Enhancement of Learning and Teaching (February, 1998). Team Teaching. City University of Hong Kong. Retrieved June 13, 2015 from http://teaching.polyu.edu.hk/datafiles/R27.html

Edem, D.A. (2003). Introduction to educational administration in Nigeria. Ibadan: Spectrum Books Limited.

Ekpoh, U.I. (2011). An assessment of knowledge management practices in Cross-River State higher institution. Nigeria Journal of Education Administration and Planning. Nigerian Association for Educational Administration and Planning. (NAEAP).

Ihekwaba, C. N. \& Osuala, R. C. (2012). Principles measurement and evaluation in education (a textbook for research and evaluations). Owerri: Zionbless Publishers Nig.

Jang, S. J. (2006). Research on the effects of team teaching upon two secondary school teachers. Educational research, 48(2), 177194.

Japanese Ministry of Education, Science, Sports and Culture, (1994). Handbook for Team Teaching. Japanese Ministry of Education, Science, Sports and Culture. 
Knight, J. (2013). The changing landscape of higher education internationalisation - for better or worse? Perspectives: Policy and Practice in Higher Education, 17(3), 84-90. doi: http://dx.doi.org/10.1080/13603108.2012.753957.

Nunan, D. (1992). Introduction. In D. Nunan, (Ed.), Collaborative Language Learning and Teaching. Cambridge: Cambridge University Press.

Ojedele, P. K. \& Fadokun, J. B. (2009). Problems and issue in higher education in Nigeria. In Babalola, J. B. \& Ayeni, A. O. (eds). Educational management: Theories and Tasks. Lagos: Macmillan Nigeria publishers limited.

Oni, J. O. (2000). Education resources: An introduction. Lagos: Abani sodipo press Limited

Quin, S. \& Kanter, S. (1984). Team-teaching: An alternative to lecture fatigue. Innovation Abstracts, 6(34). Eric document Ed251159. 